\title{
Teaching Facilitators' Perceptions of the Contribution of Three Internship Workshops Models
}

Vered Freedman, Constantin Cucoş 


\title{
Teaching Facilitators' Perceptions of the Contribution of Three Internship Workshops Models
}

\author{
Vered Freedman ${ }^{a^{*}}$, Constantin Cucoş ${ }^{b}$ \\ ${ }^{a}$ Gordon Academic College, Tchernichovsky 73, Haifa, Israel \\ ${ }^{b}$ Alexandru Ioan Cuza University, 11 Carol Boulevard, Iasi, Romania \\ *Corresponding author: veredf@gordon.ac.il
}

\section{Abstract}

\section{Keywords:}

Internship workshops; online model; 'incubator' model; facilitator; learning environment.
Internship workshops as part of induction to teaching in teacher education in Israel consist of three models: face-to-face, online, and 'incubator'. The article examines workshop facilitators' perceptions of workshops' contribution.

Mixed methods research included a questionnaire completed by 101 facilitators and statistically analyzed. Interviews were conducted with nine facilitators, three from each model and content and discourse analyzed. According to quantitative findings, no significant difference between workshop models and emotional support was perceived as stronger than professional support in all three models. Interview findings showed the clear presence of both emotional support and enhancement of a sense of self-efficacy. There were noticeable unique contributions in the two newer online and 'incubator' models, compared to the traditional face-to-face model implemented at the college. Both models promoted self-efficacy and emotional support, but each one relied on different strategies to provide the two types of contribution. In the online model, use of writing and connection with the facilitator promoted the contribution. In the 'incubator' model characteristics of the environment provided conditions for advancing support. The unique contributions have practical implications - workshops should integrate online and community-based components to promote interns' sense of well-being and professional competence as future teachers.

These findings may add valuable knowledge, which may help policy makers and interns themselves, to make better decisions on integrating the internship workshops within the prosses of teacher education.

\section{Zusammenfasung}

\section{Schlüsselworte:}

Praktikums-Workshops; Online-

Modell; 'Inkubator'-Modell;

Leiter; Lernumgebung.
Praktikumsworkshops als Teil der Einführung in den Lehrerberuf in der Lehrerausbildung in Israel bestehen aus drei Modellen: von Angesicht zu Angesicht, online und "Inkubator". Der Artikel untersucht die Wahrnehmungen der Leiter der Workshops hinsichtlich ihres Beitrags.

Die Mischmethodenforschung beinhaltete einen Fragebogen, der von 101 Leitern ausgefüllt und statistisch ausgewertet wurde. Mit neun Leitern, drei aus jedem Modell, wurden Interviews geführt und die Inhalte und der Diskurs analysiert. Den quantitativen Ergebnissen zufolge gab es keinen signifikanten Unterschied zwischen den Workshop-Modellen und die emotionale Unterstützung wurde in allen drei Modellen als stärker wahrgenommen als die professionelle Unterstützung. Die Ergebnisse der Interviews zeigten, dass sowohl die emotionale Unterstützung als auch die Stärkung des Selbstwirksamkeitsgefühls deutlich vorhanden waren. Es gab bemerkenswerte einzigartige Beiträge in den beiden neueren Online- und "Inkubator"-Modellen, verglichen mit dem traditionellen von Angesicht zu Angesicht Modell, das an der Hochschule implementiert wurde. Beide Modelle förderten die Selbstwirksamkeit und die emotionale Unterstützung, aber jedes verließ sich auf unterschiedliche Strategien, um die beiden Arten des Beitrags zu leisten. Im Online-Modell förderte die Verwendung von Schrift und die Verbindung mit dem Leiter den Beitrag. Im "Inkubator"-Modell boten Merkmale der Umgebung Bedingungen für die Förderung der Unterstützung. Die einzigartigen Beiträge haben praktische Implikationen - Workshops sollten Online- und Communitybasierte Komponenten integrieren, um das Wohlbefinden der Praktikanten und ihre berufliche Kompetenz als zukünftige Lehrer zu fördern.

Diese Ergebnisse können wertvolles Wissen hinzufügen, das Entscheidungsträgern und Praktikanten selbst helfen kann, bessere Entscheidungen über die Integration der Praktikumsworkshops in die Prozesse der Lehrerausbildung zu treffen.

\section{Introduction}

The stage of embarking on a professional career, largely known as 'induction' (Ingersoll \& Strong, 2011; Nasser Abu Alhija, Fresko \& Richenberg, 2011), is a time expressed in professional and personal difficulties that have been widely researched and discussed in the literature (Adoniou, 2016; Sözen, 2018). Various induction programs have developed over the years, where group sessions and personal mentoring 
constitute the key elements (Nasser Abu Alahija et. al., 2011; Hammer-Budnaro, 2018).

In Israel, induction programs consist of internship workshops, in which all teaching interns are required to take part (Paz \& Salant, 2012; Director General's circular, 2014). Traditional face-to-face (F2F) workshops are the most prevalent. However, online and 'incubator' workshops are two other models that have emerged in Israel and are implemented in the education system.

Empirical evidence on comparing these models is scarce. This article focuses on comparison of the three models. It presents findings of mixed method research, which examines workshop facilitators' perceptions of workshops' contribution.

\section{Theoretical background}

Internship workshops provide information about professional aspects of teaching, address dilemmas and challenging teaching situations, encourage professional reflective thinking, and formulate workable teaching patterns (Arviv-Elyashiv \& Lederer, 2011; Hammer, 2017). Based on interns' testimonies, professional contribution follows the main workshop's emotional contribution (Reingold, 2009; Fisherman, 2011). Interns have identified these workshops as a 'safe haven' in their first teaching year, a precious instrument in their emotional development (Levi-Keren \& Rosenberg, 2019; Bracha, in press). The key importance of these workshops pertains to the gap between theory and practice, a crucial factor leading to teachers' dropping out during their induction year (Adoniou, 2016; Shkedi, 2016).

The workshop models developed in Israel have similar goals and facilitation. They differ in the environment where communication among participants occurs, (F2F versus online environment) and the context where workshops are implemented (higher education institutions versus absorbing environment, i.e., school).

Online workshops emerged from the worldwide trend of Internet teaching and learning. It is conducted through discussions in forums and blogs. Online workshops' advantages include breaking time and space boundaries (Sela, 2010), the therapeutic value of writing as inviting introspection, expressing feelings and generating insights (Boniel-Nissim, 2010; Gilat, 2013) as well as decreasing one's sense of distress (Barak \& Boniel-Nissim, 2011; Kupferberg, 2013). Nevertheless, lack of self-management of learning and technological literacy may be burdensome for taking part in this model (Mioduser, Nachmias \& ForkoshBaruch, 2008).

'Incubator' model was developed to narrow the gap between the training process integration and assimilation into schools as well as to shine the spotlight onto adaptation and perception of schools as a system (Hammer, 2017). 'Incubators', existing in schools or teaching staff development centers, are linked to educational and ethical goals (Tzabary, Holzblat, Hachmon \& Pasternak, 2019; Bracha, in press) and are attended by interns, new teachers and mentor teachers. This emphasizes every role-holder's commitment to the needs of novice teachers and to paying full attention to factors promoting and hindering their success in the education system (Immanuel, 2017).

Despite the differences between the environments, there is still no broad basis of knowledge about the effectiveness of one model of workshop over the other (Rotenberg-Tadmor, 2014; Hammer-Budnaro, 2018; Levi-Keren and Rosenberg, 2019). It is important to note that these comparative studies have been limited to interns' perspective alone, and not to those of skilled facilitators leading these workshops (Zilbershtrom, 2013).

Workshop facilitators are mainly college lecturers, with an affinity to the world of counseling and treatment (Schatz-Oppenheimer, Mandel \& Zilbershtrom, 2014). Facilitators are those who are responsible for leading discourse with empathy, warmth and respect, honesty and acceptance (Yalom \& Leszcz, 2005), through confidence building debate. Similar to facilitators' significant role in F2F workshops, in online workshops, facilitators' presence has a secondary importance too. This derives from the need to compensate for the absence of their physical presence in the same space.

Further research is required in light of little knowledge gained regarding the comparison of these three workshop models, in order to gain better understanding of their effectiveness and contribution. Moreover, the search for empirical evidence on this issue, has become more important in this period. Due to the Korona crisis, all types of learning, including internship workshops, have gone online.

The current study compared the three models as seen by facilitators. Thus, it adds knowledge to help policy makers and interns reach better decisions 
regarding internship workshops in the framework of teacher education. Therefore, the research question is how facilitators perceive the contribution of internship workshops in three models, regarding emotional support, theoretical knowledge, practical tools and professional identity.

\section{Methodology}

Quantitative research participants included 101 facilitators (87 women and 14 men) from 20 Israeli teacher education colleges. A convenience sample represented facilitators from the three models $-58 \mathrm{~F} 2 \mathrm{~F}$, 26 online and 17 'incubator' model facilitators. 86\% Hebrew speakers, 9\% Arabic speakers and 5\% speakers of other languages. Qualitative research participants were nine workshop facilitators, three from each model, with at least two years' workshop facilitation seniority and rich educational background (experience $2-25$ years).

For the quantitative research, closed questionnaires for facilitators were distributed online after guarantee of complete anonymity. The questionnaire, developed for this study, addresses facilitators' perceptions towards the workshop's contribution in 12 areas (such as: Improving interpersonal communication, consolidating professional insights), to be marked from 1 to 6 . To examine general categories of the 12 areas, four aspects of the workshop's contribution (emotional support, theoretical knowledge, practical tools, and professional identity) were defined. Content was validated by expert judges and reliability was calculated using Cronbach's Alpha test.

Table 1: Reliability of the contribution of the workshop

\begin{tabular}{|l|l|c|}
\hline \multicolumn{2}{|c|}{ Category } & \multicolumn{1}{c|}{ Specific Area } \\
\hline Emotional support & Emotional support & 0.90 \\
& Expressing strengths and personal skills & 0.66 \\
\hline Theoretical knowledge & Disciplinary knowledge & Organizational knowledge \\
& Didactic knowledge & 0.72 \\
\hline Practical tools & Tools for professional coping & \\
\hline Professional identity & Improving interpersonal communication & 0.89 \\
& Improving self-efficacy to engage in teaching & \\
& Consolidating professional identity & \\
& Enhancing motivation for teaching & Consolidating professional insights \\
& Forming personal insights & \\
\hline
\end{tabular}

Since all reliability values are satisfactory, four measures were computed by averaging the responses to the areas included in each category.

For the qualitative research, online in-depth semi-structure interviews (Boyce \& Neale, 2006; Coolican, 2014) were conducted after interviewees signed informed consent forms. Interviews were flexible so as to allow focus on questions arising from facilitators' experiences. Questions referred to facilitators' views addressing the workshop's contribution to teaching interns, workshop components that affect the success of the workshop, and more. In addition to common questions, targeted questions were asked, such as how the online environment influenced the workshop's contribution to interns, the effect of location and group participants on the workshop's contribution to interns, etc. Interviews were recorded and transcribed.

\section{Findings}

Findings pertain to facilitators' perception of internship workshops' contribution in three models. The specific contributions were categorized into four domains: emotional support, theoretical knowledge, practical tools, professional identity. A two - way analysis of variance (MANOVA) was conducted to compare the three workshop models' perceived contribution. The results are presented in Figure 1.

Figure 1: Workshop Contribution by model and domain of contribution

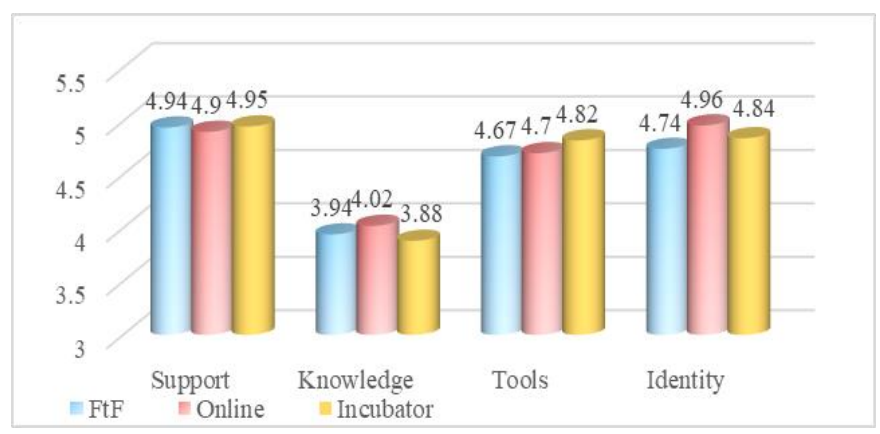


Workshop model did not yield a significant effect $(\mathrm{F}(2,97)=.10$, N.S. indicating that the general contribution score (mean of the four domains) was not significantly different in the three workshop models.

Furthermore, a significant main effect of domain was found $(\mathrm{F}(3,97)=45.99, \mathrm{p}<.001$. Post-hoc Bonferroni comparisons $(\mathrm{p}<.05)$ were conducted to identify specific differences among the four domains. The analysis revealed that workshop contribution in emotional support was significantly higher than in developing identity and providing tools, which was higher than the contribution to supplying knowledge. Thus, the hierarchy was: Support > Identity, Tools >
Knowledge. No significant interaction between workshop - model - domain were found, indicating that the hierarchy of domains was the same for all three models.

The qualitative analysis supported these findings and illuminated them more accurately. Interviews were analyzed according to grounded theory (Corbin \& Strauss, 2008) and followed by discourse analysis (Coolican, 2014). Two major types of contribution emerged: (a) psychological - expressed in providing emotional support and (b) professional - empowering the sense of self-efficacy. The two types of contributions with specific strategies and exemplary citations are presented in Table 2.

Table 2: Types of Contribution according to qualitative analysis

\begin{tabular}{|c|c|c|}
\hline Type of contribution & strategies & citations \\
\hline \multirow[t]{4}{*}{$\begin{array}{l}\text { Emotional support } \\
\text { (psychological contribution) }\end{array}$} & \multirow[t]{2}{*}{$\begin{array}{l}\text { Normalize personal } \\
\text { experiences }\end{array}$} & $\begin{array}{l}\text { They actually learn to identify the system and they come out of some sort of } \\
\text { bubble }\end{array}$ \\
\hline & & $\begin{array}{l}\text { They understand 'hold on, it is not only in my discipline'. It happens to } \\
\text { everyone }\end{array}$ \\
\hline & \multirow[t]{2}{*}{$\begin{array}{l}\text { Strengthen sense of } \\
\text { belonging }\end{array}$} & $\begin{array}{l}\text { The fact that they sit together in a group of people who are in the same } \\
\text { situation }\end{array}$ \\
\hline & & There is an atmosphere of togetherness and of genuine collegiate learning \\
\hline \multirow[t]{5}{*}{$\begin{array}{l}\text { Sense of self-efficacy } \\
\text { (professional contribution) }\end{array}$} & \multirow[t]{2}{*}{$\begin{array}{l}\text { Solution focused } \\
\text { discourse }\end{array}$} & $\begin{array}{l}\text { Understanding there is a solution is important. if not, they won't continue in } \\
\text { the system }\end{array}$ \\
\hline & & It's okay to fail, it's okay to cope and that in itself some sense of self-efficacy \\
\hline & \multirow{2}{*}{$\begin{array}{l}\text { Strengths focused } \\
\text { discourse }\end{array}$} & When sharing, the group is an echo for voices existing in him \\
\hline & & $\begin{array}{l}\text { The group's request to hear and give feedback awaken those of colleagues, } \\
\text { who are seeking resources within themselves }\end{array}$ \\
\hline & Practical knowledge & $\begin{array}{l}\text { He does not know what to expect ... when we ask and direct, it gives them a } \\
\text { strength }\end{array}$ \\
\hline
\end{tabular}

Both quantitative and qualitative analysis suggest that the contribution of the workshop is manifested in two major areas: emotional and professional contribution. Each one of these areas contains several dimensions.

Two categories emerged from the interviews regarding 'emotional support'. The first, normalizing personal experiences occurring on an intrapersonal level causing a change in interns' personal feelings. Metaphors chosen ('some sort of bubble in which they immersed themselves', 'breathing space'), reflect a sense of relief from a feeling of suffocation, which intensify the normalization. Strengthening sense of belonging is the second category, expressed by reinforcing links between individual interns and the group. Facilitators emphasized the important role of a group. Discourse analysis revealed metaphors ('thrown into the lion's den', 'in the same boat') contribute to understanding the unique meaning of strengthening the sense of belonging in interns' experiences of pressures and sense of danger. The message is that no intern is left to cope alone with challenges, but the entire group is recruited thus reinforcing each workshop participant's ability.

The second type of contribution emerged on the professional level - strengthening interns' sense of self-efficacy. It comprises of three strategies. The first strategy is participating in solution focused discourse. In workshop sessions, interns raised dilemmas and difficulties, and discourse emphasized finding solutions. The knowledge that it is possible, results in practical optimism and alleviates the transition from passivity to activity - a key aspect of educational work. The second strategy is focusing the discourse on strengths. Sharing and discussing professional dilemmas emphasizes interns' strengths. Often, when sharing experiences and an individual's ways of coping, the group echoes the voices the individual did 
not hear. The group's wish to hear all details, questions asked and feedback provided awakened both the individual intern's internal resources and those of colleagues, also seeking these resources within themselves. The third strategy is the acquisition of practical knowledge. Discourse and addressing issues from the world of teachers also contribute to a sense of professional self-efficacy, both by considering interns' professional duties and expectations and by planning and preparing for work stages throughout the year.

Interviews disclosed unique contributions of the newer workshop models. The online model particularly influenced self-efficacy. The discourse is documented and as such it is possible to process answers more profoundly and gain a better perspective on the process of professional development after the induction year. The other two models lack these advantages. Furthermore, time and place constraints invite profound communication between interns and facilitator. Although all models enable establishing contacts, only the online model offers structured access by using personal blogs. Online workshop facilitators testified that this sharing is different from the tasks that are open to all participants or the group's forum. This personal communication with the facilitator can promote self-efficacy and provides meaningful emotional support.

In the 'incubator' model, characteristics of the environment provide conditions for lending unique support. The model involves many factors engaging in absorbing interns into the education system, and as such provides varied ways of support. This contributes to interns professionally by promoting self-efficacy, and emotionally by creating a sense of protection. It does not occur among interns themselves or between facilitator and interns as in other models but among all role-holders who participate in 'incubator' sessions.

\section{Discussions}

This mixed-method research examined the contribution of internship workshops, which are part of interns' induction to teaching, by focusing on perspectives of facilitators in three workshop models: F2F, online, and 'incubator'.

Quantitative findings found no significant differences between the three models regarding their contribution to interns. Workshop contribution to emotional support was significantly higher than to developing identity and providing tools, which was higher than contribution to supplying knowledge.
These findings are supported by qualitative findings expressing emotional support and sense of selfefficacy. Hence, it can be said, that workshop contribution is emotional and professional. This claim is supported by the professional literature, emphasizing emotional support as workshops' main aim (Reingold, 2009; Fisherman, 2011) and indicating developing self-efficacy as a vital component.

Workshops' contribution to promoting a sense of normalization can be explained against a background of difficulties characterizing the process of induction to teaching. Research revealed that induction is experienced as a period of crisis, with components of shock and loneliness (Tzabar-Ben Yehoshua, 2001; Bar-Tal et al., in press;). Despite partnership and work relationships created in educational space, and although there are other interns in schools, there is no time or place to lay down one's hat and reveal personal experiences that are mostly normative and not unique to individual interns.

Promoting a sense of self-efficacy through workshops has been reported in previous studies (Rotenberg-Tadmor, 2014; Hammer-Budnaro, 2018), but in this study it is the mechanisms by which workshop processes enhance interns' sense of selfefficacy. Participation in discourse focused on solutions and strengths were found to be two of the ways intended to improve interns' self-efficacy.

While most studies conducted to date were based on interns' views, this study innovates what is known in the literature by presenting facilitators' voices and reflecting their perspectives. This strengthens the validity of workshops' contribution to teacher education in the two identified foci.

As well as factors common to the three models, there were unique contributions in the two newer online and 'incubator' models, compared to the traditional F2F model implemented at the college. Both models promoted self-efficacy and emotional support but relied on different strategies to provide the two types of contribution. Two interrelated assets of the online model were the use of writing and connection with the facilitator. Writing on a forum resembles an intra-personal discourse through which a person's inner voice is exposed to both writer and reader (Dickman, 2005). In addition, a cognitive advantage of writing is expressed by it helping organized and creative thought (Freedman \& Cucos, 2019) 
Another allegedly surprising finding is the meaningful connection with the facilitator. Indeed, accepted thinking is that the role of teachers in online learning is less dominant, but it turned out, that even in online workshops, learners need the full presence of facilitators as a source of support. This finding corresponds with studies that examined learners' expectations from teachers' presence in an online environment (Peacock et al., 2020; Reupert, Maybery, Patrick \& Chittleborough, 2010)

The unique contribution of the 'incubator' model results from the many factors responsible for absorbing interns into the education system. This is supported by previous studies on 'incubator' workshops (Levi-Keren \& Rosenberg, 2019) It does not occur in other models but is made up of all role-holders who take part in 'incubator' sessions. The study provides empirical support to the theoretical perception of 'incubator' workshops (Immanuel, 2017), which is consistent with the current perception of inclusion, community and integration of all systems.

The key finding indicating the emotional and professional contribution of each model is surprising in that the online model has been underappreciated compared to both F2F models. The expectation was that the online model would contribute less because F2F encounters are considered critical for workshop success. Congruent with previous comparative research findings (Hammer-Budnaro, 2018; Rotenberg Tadmor, 2014), this study suggests adopting the online model alongside the other two. Interestingly, online workshop constituted $20 \%$ of internship workshops as instructed by the Ministry of Education, but the COVID-19 crisis has expedited assimilation of the online model in the entire education system, including internship workshops. In addition to asynchronous learning, which has characterized the online model to date, the workshops were conducted during this period both in synchronous and asynchronous sessions, both online.

\section{Conclusions}

The online environment does not replace the F2F one but rather extends and complements possibilities. Mixed environments have been shown to generate greater satisfaction with learning than programs that are fully online (Cole et al., 2014), and that learners experience a greater sense of community than in traditional programs (Chen \& Chiou, 2014).
From a practical point of view, when planning interns' workshops, it is worthwhile integrating an online component and communication with community to promote interns' sense of well-being and their professional self-efficacy as future teachers.

Hence, there is also a response to the system's needs, saving physical resources without damaging the requirements of the internship workshop. The findings are likely to help identify interns suitable for each workshop model. Presenting the feature of each model to student teachers at the end of their $3^{\text {rd }}$ year, may contribute to their accurate impression of each.

This study was based on workshop facilitators. One limitation was that it looked solely at facilitators' perceptions. It is important to hear the opinion of interns to compare and examine consistencies between perspectives. Moreover, data was collected during workshops and therefore perspective is limited to immediate observations. It would be appropriate to explore a retroactive view allowing for learning about the long-term effects of all three workshop models' contribution to integration into teaching.

Authors note: The authors had equal contributions to this article.

Vered Freedman is a $\mathrm{PhD}$ student in education, with a Master's degree in educational counseling. Lecturer at the department of Early Childhood at the Gordon Academic College and facilitator of professional development workshops at the induction to teaching stage. Her areas of interest and research include online teaching, collaborative learning, and interpersonal communication. She is currently researching teaching internship workshops with an emphasis on learning environments.

Constantin Cucoş is a $\mathrm{PhD}$ Professor at the Faculty of Psychology and Educational Sciences (Department for Teacher Training), for over 30 years, at the "Alexandru Ioan Cuza" University of Iasi. He is the author of over 15 author volumes and over 200 studies in collective volumes or specialized journals. Areas of competence: training of trainers, philosophy of education, pedagogy of culture, religious education, aesthetic education, intercultural pedagogy.

\section{References}

Adoniou, M. (2016). Don't let me forget the teacher I wanted to become. Teacher Development, 20(3), 348363. 
Arviv-Elyashiv, R., \& Lederer, D. (2011). Internship Workshop - Mixed or Special, Dapim, 52, 46-71. (In Hebrew).

Barak, A., \& Boniel -Nissim, M. (2011). The Internet for the help of adolescents: Therapeutic value of blog writing. Mifgash, 34, 9-30. (In Hebrew).

Bar-Tal, S. Hemo, N. Snapir, Z., \& Gilat, Y. (In press). Choosing Education: challenges in Second Career Teachers' Induction to Teaching.

Boniel-Nissim, M. (2010). The Therapeutic Value of Adolescents' Blogging about Social-Emotional Difficulties. (Doctoral dissertation). University of Haifa, Israel. (In Hebrew).

Boyce, C., \& Neale, P. (2006) Conducting In-Depth Interview: A Guide for Designing and Conducting InDepth Interviews for Evaluation Input. Pathfinder International Tool Series, Monitoring and Evaluation-2

Bracha, E. (in press). Contribution of the Workshop Practice Based on Urban Hammama Model. Rav Gvanim - Mehkar VaSiach, Gordon Academic College of Education, Haifa, Israel. (In Hebrew).

Chen, B. H., \& Chiou, H. H. (2014). Learning style, sense of community and learning effectiveness in hybrid learning environment, Interactive Learning Environments, 22(4), 485-496.

Cole, M. T., Shelley, D. J., \& Swartz, L. B. (2014). Online Instruction, E-Learning, and Student Satisfaction: A Three-Year Study, International Review of Research in Open \& Distance Learning, 15(6), 111-131.

Coolican, H. (2014). Research Methods and Statistics in Psychology. New York: Psychology Press.

Corbin, J., \& Strauss, A. (2008). Basics of qualitative research: Techniques and procedures for developing grounded theory. London: Sage.

Dickman, N. (2005). Writing as a vehicle for reflecting and enhancing learning process of mathematics teachers in the course of becoming mathematics teachers' educators. (Doctoral dissertation). Technion, Haifa, Israel. (In Hebrew).

Director General's Circular (2014). Implementation Circular Towards the 2005 School Year - Teaching Internship. Jerusalem, Ministry of Education. (In Hebrew).

Fisherman, S. (2011). The novice's organizational literacy: school in the novice teachers' perception and as presented to them by the principal. In: O. SchatzOppenheimer, D. Maskit, \& S. Zilbershtrom (Eds.), Being a Teacher on the Induction Route. (pp. 151-180). Israel: Mofet. (In Hebrew).

Freedman, V., \& Cucoş, C. (2019). Model combining learning environments (online and face-to-face) in teaching internship workshops. European Proceedings of Social and Behavioral Sciences, Available at: https://www.researchgate.net/publication/342255576_ Model_Combining_Learning_Environments_In_Teachi ng_Internship_Workshops,

DOI: 10.15405/epsbs.2020.06.6.

Gilat, I. (Ed.), (2013). Only on the Internet Can I Share What I Am Going Through. Mental Help in an Online
Environment (pp. 100-114). Tel Aviv: Mofet. (In Hebrew).

Hammer, D. (2017). Leading Change Processes AcademiaField at the Induction: A three- Year Perspective. Hachinuch Usvivo, 39, 27-50 (In Hebrew).

Hammer-Budnaro, D. (2018). Online workshop versus face-to-face workshop during the induction phase. Dapim, 67, 161-183. (In Hebrew).

Immanuel, D. (2017). Teachers' incubator at the Induction to Teaching Stage retrieved from: http:/cms.education.gov.il/EducationCMS/Units/Staj/ Mitmahim/MeidaAlsadnaot/Chamamot.html.

Ingersoll, R., \& Strong, M. (2011). The Impact of Induction and Mentoring Programs for Beginning Teachers: A Critical Review of the Research. Review of Education Research. Vol. 81(2), pp. 201-233.

Kupferberg, I. (2013). Constructing online interpersonal communication through discourse resources. In I. Gilat (Ed.), Only on the Internet Can I Share What I Am Going Through. Mental Help in an Online Environment (pp. 100-114). Tel Aviv: Mofet. (In Hebrew).

Levi-Keren, M., \& Rosenberg, K. (2019). Novice Teachers' Perceptions towards the Induction Process: An Interim Report. Kibbutzim College of Education, Technology and the Arts (In Hebrew).

Mioduser, D., Nachmias, R., \& Forkosh-Baruch, A. (2008). New Literacies for the Knowledge Society. In J. Voogt \& G. Knezek (Eds.), International Handbook of Information Technology in Primary and Secondary Education (pp. 23-42). New York, NY: Springer.

Nasser Abu Alhija, P., Fresko, B., \& Reichenberg, R. (2011). The First Year of Teaching - an Overview. In O. Schatz-Oppenheimer, D. Maskit \& S. Zilbershtrom (Eds.), Being a Teacher on the Induction Route. (pp. 5587). Israel: Mofet. (In Hebrew).

Paz, D., \& Salant, A. (2012). Teacher Induction-Literature Review. Tel Aviv: Moet Institute (In Hebrew).

Peacock, S., Cowan, J., Irvine, L., \& Williams, J. (2020). An Exploration into the Importance of a Sense of Belonging for Online Learners. The International Review of Research in Open and Distributed Learning, 21(2), 18-35. https://doi.org/10.19173/irrodl.v20i5.4539.

Reingold, R. (2009). The Novice Teacher and Programs for Successful Absorption. Panim, 47, 79-85. Available from:

https://www.itu.org.il/?CategoryID=1544\&ArticleID=1 4146 (In Hebrew).

Reupert, A., Maybery, D., Patrick, K., \& Chittleborough, P. (2010). The importance of being human: Facilitators' personal presence in distance programs. International Journal of Teaching and Learning in Higher Education, 21(1), 47-56.

Rotenberg-Tadmor, Y. (2014). Enhancing Outcomes in Teacher Internship workshops: Comparing Face-toFace with Online Groups (Doctoral dissertation). University of Haifa, Haifa. (In Hebrew).

Schatz-Oppenheimer, O., Mandel, B., \& Zilbershtrom, S. (2014). Mentoring and Accompanying Interns and 
Novice Teachers. Jerusalem: Ministry of Education, Teaching Department - Induction and Internship (In Hebrew).

Sela, O. (2010) Can a virtual 'place' replace or enrich a physical place? Dvarim, 3, 123-134. (In Hebrew).

Shkedi, A. (2016). They remained in the Classroom: Narratives of Outstanding Teaching Students. Raanana: Mofet. (In Hebrew).

Sözen, H. P. (2018). Challenges of novice teachers. IJAEDU- International E-Journal of Advances in Education. IV (12), 278-282.

Tzabar-Ben Yehoshua, N. (2001) (Editor). Traditions and Genres in Qualitative Research Philosophies, Strategies and Advanced Tools. Mofet: Tel Aviv.
Tzabary, A., Holzblat, R., Hachmon, M., \& Pasternak, I. (2019, June). The expert in teaching was once a beginner: Talpiot's MIT research results. Paper presented at the 7th international conference on teacher education: The story of innovation in teacher education, Mofet Institute, Tel Aviv, Israel.

Yalom, I., \& Leszcz, M. (2005). The theory and practice of group psychotherapy (5th ed.). New York, NY: Basic.

Zilbershtrom, S. (2013). The policy of the Department of Internship and Induction in Teaching. In S. Shimoni \& A. Avidav-Ungar (Eds.), On the continuum: Training, induction and professional development of teachers policy, theory and practice (pp. 95-100). Mofet: Tel Aviv. (In Hebrew). 